\title{
Bootstrapped Durbin- Watson Test of Autocorrelation for Small Samples
}

\section{Jesmin Akter}

Assistant Professor, Faculty of Business, ASA University Bangladesh, BANGLADESH

\begin{abstract}
The Durbin-Watson (DW) test is the most widely used test for autocorrelation of a first order in regression analysis. The critical value of DW test depends on $X$ matrix. As a result, the DW test statistic falls sometime in the inconclusive region. For large sample, the DW test can be used for normal distribution. In this paper, we proposed a bootstrap critical value for small sample and compared the power properties with other procedures. Monte-Carlo study shows that the bootstrapped DW test performs better than the usual DW test with the help of power.
\end{abstract}

JEL Classification Codes: C12, C1

Keywords: Bootstrap, Durbin-Watson test, Autocorrelation, Recursive Bootstrap

$10 / 20 / 2014$

Source of Support: Nil, No Conflict of Interest: Declared.

How to Cite: Akter J. 2014. Bootstrapped Durbin- Watson Test of Autocorrelation for Small Samples ABC Journal of Advanced Research, 3, 137-142.

This article is is licensed under a Creative Commons Attribution-NonCommercial 4.0 International License.

Attribution-NonCommercial (CC BY-NC) license lets others remix, tweak, and build upon work non-commercially, and although the new works must also acknowledge \& be non-commercial.

\section{INTRODUCTION}

In time series or econometric analysis, our aim is to forecast or predict future behavior of variables. It is to estimate the unknown parameters of the model for making the predictions of the natures of variables. But the estimates of the parameters may be inefficient if the error term of the model does not follow certain assumptions. The assumption of the model may not justify in all cases. Usually, autocorrelation problem arises in time series data. If we used in usual testing procedure despite autocorrelation whatever conclusion may be mislead. Thus, it is necessary to detect the existence of autocorrelation in a given series at the initial stage.

The Durbin-Watson (DW) test is the most widely used test for autocorrelation in regression model. But, this test has certain limitations, such as:

- Critical value depends on X-matrix, which leads to "indeterminate range".

- Only applicable for first order autocorrelation,

- Not suitable for dynamic model.

Durbin-Watson (DW) test is not applicable for small samples. In a case of small sample, DW test cannot be applied and in such a situation bootstrap procedure may be a solution to this problem. In this paper, we propose a bootstrapped DW-type test and compare the power properties by Monte-Carlo simulation. 
The plan of this paper is as follows: In next section, discuss the model and hypothesis for testing first order autocorrelation. Third section discusses the techniques of bootstrapped DW statistic. In the section four, discuss the Monte-Carlo simulation study. Simulation study is carried out in section five.

\section{Materials AND Methods: Model AND Hypothesis}

The model

Let us, consider the following regression model $Y=\beta X+u$

Where, $Y$ and $u$ are $(n \times 1), X$ is $(n \times \mathrm{k}), \beta$ is $(k \times 1)$ and $\mathrm{n}$ denotes the number of observations. The disturbance vector, $\boldsymbol{u}$ is normally distributed with $E(u)=0$ and $\mathrm{E}\left(u u^{\prime}\right) \stackrel{\prime}{=} \Omega, \Omega$ is positive definite. We assume that the disturbance term follows a stationary $\mathrm{AR}(1)$ process of the form

$$
u_{t}=\rho u_{t-1}+\epsilon_{t} \text {, where, } \epsilon_{t} \sim N I D\left(0, \sigma^{2}\right)
$$

Hypothesis

In order to test the autocorrelation in linear regression model as defined in (1) with disturbance term $u$, which follows an AR (1) process of the form (2), the hypothesis are as follows:

$$
H_{0}: \rho=0 \text { against } H_{a}: \rho>0
$$

\section{BOOTSTRAP DW (BDW) TESTS FOR AUTOCORRELATION}

Many research work have been conducted considering bootstrapped based solution of the problem of autocorrelation. (Jeong and Chung (2001), MacKinon, G. J. (2005)). Davidson and Mackinnon (2002) applied a recursive bootstrap procedure to test of autocorrelation in the presence of lagged dependent variables. Their simulation results show that the bootstrap would be a useful tool for autocorrelation tests. The empirical sizes of bootstrap tests are acceptable, if not perfect. The power of a 'parametric' bootstrap test is closed to the nearest one except in some abnormal cases with a small number of observations. (Abrahamse, A. P. J. and Koerts (1969)).

In this study suggest a bootstrap test for autocorrelation, is called 'Bootstrapped DW( BDW) test'. Firstly, BDW test uses the critical values from the empirical bootstrap distribution and eliminates the indeterminate range of the DW test. Elimination of the inconclusive range expected to improve the power of the DW test. Secondly, the BDW test is robust to distributional assumptions. The $\left(d_{L}, d_{U}\right)$ adjustment as well as the other approximated test procedures based on the normality assumption. Bootstrap utilizes the information embedded in a given finite sample; bootstrapping is expected to provide better finite sample properties then the asymptotic testing procedure.

It's not a question how much accurate the bootstrap DW statistics. One decide how to resample the data, how to construct the empirical distribution, whether to construct the empirical distribution under the null hypothesis or under the alternative hypothesis (i.e. at a given sample), etc. We apply the following recursive bootstrap procedure to the DW statistic.

i. $\quad$ Estimate $\hat{\beta}$ of equation (1) by OLS and compute $\widehat{u}$.

ii. Estimate $\hat{\rho}$ of equation (2) by OLS and compute $\hat{\varepsilon}$.

iii. Resample $\hat{\varepsilon}$ to construct a bootstrap residual vector $\varepsilon^{*}$. 
iv. Recursively construct a bootstrap residual vector $u^{*}$ by equation (2). At this stage, to impose the null hypothesis $H_{0}: \rho=0$. As a result, $u^{*}$ becomes identical to $\varepsilon^{*}$.

v. Using $X$ and $u^{*}$ create the 'fake' data by $y^{*}$ by equation (1).

vi. Using $X$ and $y^{*}$ we recomputed the DW statistic $d^{*}$.

vii. Repeat step (III)-(VI) to construct the empirical distribution of $d^{*}$.

viii. We reject the null hypothesis when $d>d_{j}^{*}$. The bootstrap critical value $c_{\alpha}^{*}$ is the $(1-\alpha)$ quintile of the $d_{j}^{*}$. This is simply a number $(1-\alpha)^{*} B$ in the list of $d_{j}^{*}$, sorted from smallest to largest.

\section{Monte-CARLo Simulation}

To verify the finite sample performance of the bootstrap tests suggested in this paper, perform a Monte-Carlo study. We consider the three alternative tests for autocorrelation in the regression model: the original DW test, the BDW test and the Asymptotically DW (ADW) test. (see, for example, Gujarati (2003, pp471-472)).

The regression model (1) along with the first order error structure (2) is used in the simulation study. We consider a hypothesis of the form $H_{0}: \rho=0$ against $H_{a}: \rho>0$. In Monte-Carlo simulation, all $\beta$ 's are set to 1 , and the $X^{\prime}$ s are created by random picks from an uniform distribution over the range 0 to 1 . The white noise error $\epsilon_{t}$ is a standard normal. The degree of autocorrelation is controlled by changing the value of $\rho$. In this study considered 10 different values of $\rho$ : $0.0,0.1, \ldots . .0 .9$ and seven different sample sizes; $10,15,20,30,50,100$, and 200 . The number of bootstrap replication is set to 200 , and the number of simulation is 1000 . The normal size of the tests is set to 0.05 .

\section{Results AND Discussion}

Table 1 and 2 present the Monte-Carlo study and the visual inspection of the results are shown in figure 1and 2. Table 1 and table 2 represent size and power of the three different types of DW test discussed in this paper for $n=15$ and $n=20$. Figure 1-2 present the power of three tests of result included in table 1-2. The vertical axis of the figures measures the power of three tests, and the horizontal axis represents the value of $\rho$.

From the results, it is observed several important implications. First, the original DW test has unacceptable small sample properties. The power of the DW test is not satisfactory when (n-k) is small. For example, when $n=20$ and $k=10$, the power of DW is 0.204 , when $n=10$, and $k=3$, the power is 0.185 and when $n=15, k=10$, the power is as low as 0.075 even for $\rho=0.9$.

But the BDW test shows better finite sample properties then DW test. For example, when $\mathrm{n}=20$, and $\mathrm{k}=10$, the power of $\mathrm{BDW}$ is 1.0 , when $\mathrm{n}=10$, and $\mathrm{k}=3$, the power is 0.994 and when $\mathrm{n}=15$, and $\mathrm{k}=10$, the power is 0.813 for $\rho=0.9$. These powers are always higher than the power of the DW and ADW.

It is evident from the tables and all figures that the power of BDW test is always higher than the usual DW test including Asymptotic DW test for different values of $\mathrm{n}$ and $\rho$ considered in this study.

\section{Conclusions}

In this paper, a bootstrap Durbin Watson test has been proposed. Monte-Carlo study indicates that the bootstrap test show higher power than the existing DW and ADW tests for small sample. 


\section{REFERENCES}

Abrahamse, A. P. J and Koerts (1969). A comparison between the power of the Durbin Watson test and the power of the BLUS test, Journal of Statistical Association, 64,938-948.

Basak, T., Rois, R., and Majumder, A. K. (2003) One sided version of the Brush-Godfrey test for testing Higher -order Autocorrelation-A distance based approach, Role of the Statistician in Achieving the Millennium Development Goals, conference papers, Bangladesh Statistical Association.

Canjels, E. (2002). A Permutation Version of the Durbin-Watson Test for Serial Correlation, Working Paper, New School University, New York.

Draper, N. R., and Smith, H. (1966). Applied Regression Analysis, John Wiley and Sons, New York.

Durbin, J., and Watson, G. S. (1971). Testing for serial correlation in least squares regression, Econometrics, 58, 1-19.

Gujarati, D. N. (2003). Basic Econometrics, $4^{\text {th }}$ edition, McGraw Hill, New York.

Leong, J. and Chung, S. (2001). Bootstrap test for autocorrelation, Computational Statistics and Data Analysis, 38 (1), 49-69.

MacKinon, G. J. (2002). Bootstrap inference in econometrics, Canadian Journal of 615-645.

MacKinon, G. J. (2005). Bootstrap methods in econometrics, working paper, Department of Economics, Queen's University, Canada.

Majumder, A. K. (1999). One sided and partially one sided hypothesis testing in econometrics, An unpublished thesis, Monash University, Australia.

Shively, T. S., Ansley, C. F. and Kohn, R. (1990). Fast evaluation of the distribution of the DurbinWatson and other invariant test statistics in time series regression, Journal of American Statistical Association, 85, 676-685. 


\section{APPENDIX A}

TABLE1: SIZE AND POWER OF THE ORIGINAL DW, BDW AND ASYMPTOTIC DW TESTS WHEN $n=15, \alpha=.05, \rho>0$

\begin{tabular}{|c|c|c|c|c|c|c|c|c|c|c|c|}
\hline \multirow[t]{2}{*}{$\mathbf{k}$} & \multirow{2}{*}{$\begin{array}{l}\text { Test } \\
\rho\end{array}$} & \multicolumn{10}{|c|}{ Size $\quad$ Power } \\
\hline & & 0.0 & 0.1 & 0.2 & 0.3 & 0.4 & 0.5 & 0.6 & 0.7 & 0.8 & 0.9 \\
\hline \multirow{4}{*}{3} & DW & 0.049 & 0.063 & 0.079 & 0.101 & 0.169 & 0.201 & 0.318 & 0.418 & 0.504 & 0.611 \\
\hline & BDW & 0.049 & 0.074 & 0.181 & 0.362 & 0.568 & 0.789 & 0.903 & 0.960 & 0.983 & 0.994 \\
\hline & ADW & 0.05 & 0.074 & 0.127 & 0.186 & 0.259 & 0.309 & 0.416 & 0.553 & 0.629 & 0.723 \\
\hline & DW & 0.049 & 0.045 & 0.067 & 0.071 & 0.087 & 0.113 & 0.158 & 0.203 & 0.231 & 0.255 \\
\hline \multirow[t]{3}{*}{5} & BDW & 0.049 & 0.058 & 0.099 & 0.180 & 0.294 & 0.430 & 0.565 & 0.661 & 0.730 & 0.810 \\
\hline & ADW & 0.05 & 0.063 & 0.104 & 0.122 & 0.153 & 0.185 & 0.252 & 0.303 & 0.326 & 0.366 \\
\hline & DW & 0.049 & 0.041 & 0.050 & 0.066 & 0.072 & 0.067 & 0.055 & 0.084 & 0.072 & 0.075 \\
\hline \multirow[t]{2}{*}{10} & BDW & 0.049 & 0.208 & 0.522 & 0.809 & 0.937 & 0.981 & 0.992 & 0.996 & 0.996 & 0.982 \\
\hline & ADW & 0.05 & 0.056 & 0.078 & 0.092 & 0.105 & 0.102 & 0.106 & 0.117 & 0.108 & 0.106 \\
\hline
\end{tabular}

TABLE2: SIZE AND POWER OF THE ORIGINAL DW, BDW AND ASYMPTOTIC DW TESTS WHEN $n=20, \alpha=.05, \rho>0$

\begin{tabular}{|c|c|c|c|c|c|c|c|c|c|c|c|}
\hline $\mathbf{k}$ & Test & \multirow{2}{*}{\multicolumn{4}{|c|}{ Size }} & \multicolumn{6}{|c|}{ Power } \\
\hline & $\rho$ & 0.0 & & & 0.3 & 0.4 & 0.5 & 0.6 & $\begin{array}{l}0.7 \\
\end{array}$ & 0.8 & 0.9 \\
\hline \multirow{4}{*}{3} & DW & 0.049 & 0.067 & 0.098 & 0.156 & 0.260 & 0.372 & 0.526 & 0.669 & 0.786 & 0.872 \\
\hline & BDW & 0.049 & 0.125 & 0.354 & 0.646 & 0.864 & 0.964 & 0.992 & 0.998 & 0.999 & 0.999 \\
\hline & ADW & 0.05 & 0.084 & 0.152 & 0.266 & 0.341 & 0.485 & 0.615 & 0.735 & 0.838 & 0.914 \\
\hline & DW & 0.049 & 0.049 & 0.079 & 0.126 & 0.171 & 0.255 & 0.343 & 0.464 & 0.540 & 0.648 \\
\hline \multirow[t]{3}{*}{5} & BDW & 0.049 & 0.104 & 0.250 & 0.498 & 0.717 & 0.868 & 0.955 & 0.968 & 0.992 & 0.998 \\
\hline & ADW & 0.05 & 0.071 & 0.132 & 0.212 & 0.270 & 0.367 & 0.450 & 0.572 & 0.667 & 0.775 \\
\hline & DW & 0.049 & 0.058 & 0.065 & 0.074 & 0.077 & 0.104 & 0.115 & 0.153 & 0.157 & 0.204 \\
\hline \multirow[t]{2}{*}{10} & BDW & 0.049 & 0.487 & 0.689 & 0.802 & 0.899 & 0.942 & 0.978 & 1 & 1 & 1 \\
\hline & ADW & 0.05 & 0.063 & 0.080 & 0.110 & 0.120 & 0.153 & 0.183 & 0.226 & 0.262 & 0.291 \\
\hline
\end{tabular}




\section{APPENDIX B}

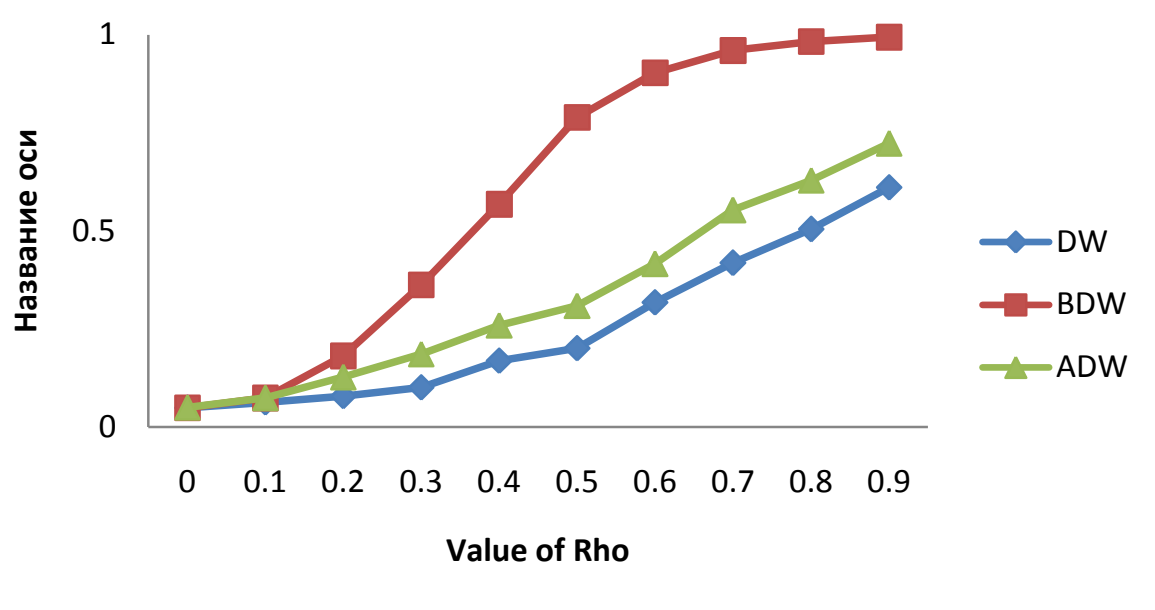

Figure 1: Illustration of the power curve of DW, and ADW test when $n=15, k=3$, with the proposed Bootstrapped based Durbin-Watson (BDW) test.

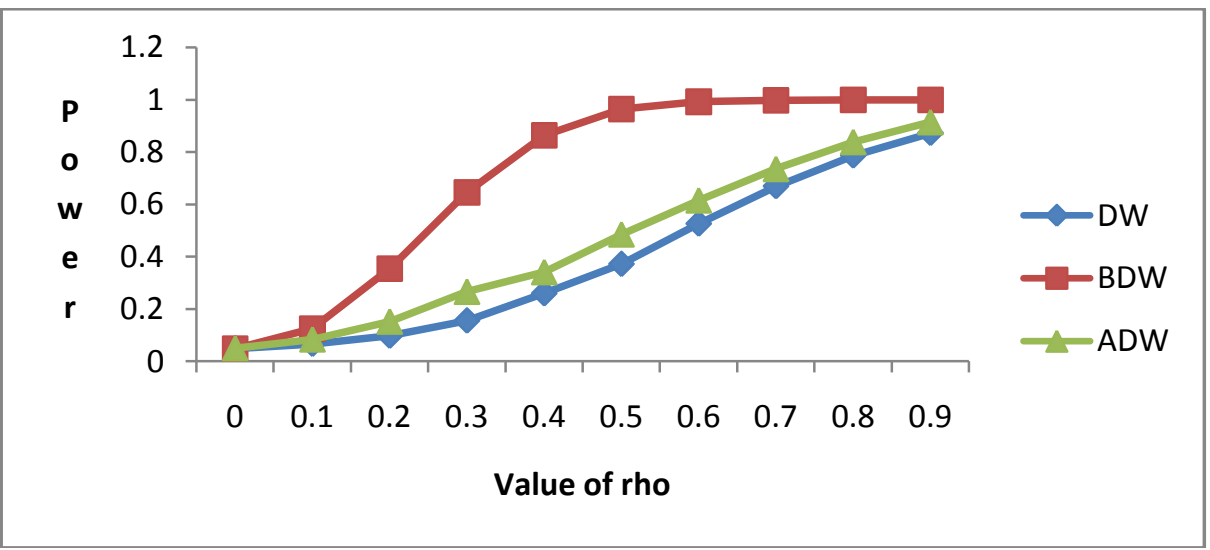

Figure 2: Illustration of the power curve of DW, and ADW test when $n=15, k=3$, with the proposed Bootstrapped based Durbin-Watson (BDW) test. 